\title{
Estudo Anatomoclínico do Carcinoma Ductal Invasivo da Mama em Pacientes Axila-Negativas Associado à Identificação dos Receptores de Estrogênio.
}

Autor: Gilberto Uemura

Orientador: Prof. Dr. Laurival A. de Luca

Dissertação apresentada ao curso de Pós-Graduação em Ginecologia da Faculdade de Medicina de Botucatu, UNESP, para obtenção do Título de Mestre, em 17/8/98.

A incidência preocupante, as desastrosas conseqüências na saúde orgânica e psíquica e os elevados indices de mortalidade conferem ao câncer de mama características de grave problema de saúde pública mundial. Os aspectos heterogêneos desta doença associados ao mau prognóstico tem incentivado a identificação de fatores que permitam a melhor compreensão do seu comportamento biológico. Estes fatores podem ser divididos em anatomopatológicos e biológicos. As pacientes axila-negativas são as que apresentam melhor taxa de sobrevida em relação às pacientes axila-positivas. Entretanto cerca de 30\% das pacientes axila-negativas apresentam pior prognóstico, com recidiva sistêmica do câncer. Analisamos, retrospectivamente, 54 pacientes axila-negativas através de dados clínicos e anatomopatológicos, correlacionando com a expressão do receptor de estrogênio. A idade variou de 25 a 80 anos (média de 57 anos) e o tamanho do tumor entre 1 a $20 \mathrm{~cm}$ (média de $3,42 \mathrm{~cm}$ ). Realizamos associação entre vários parâmetros clínicos e anatomopatológicos e encontramos significado estatístico entre tamanho de tumor e óbito, grau histológico e expressão do receptor de estrogênio, período livre de doença e grau histológico, período livre de doença e expressão de receptor de estrogênio, sobrevida e tamanho do tumor e sobrevida e grau histológico.

Palavras-chave: Mama: câncer. Receptor de estrógenos. Câncer: prognóstico.

RBG0 21(5):301-302, 1999

\section{Sangramento Uterino Anormal na Adolescência}

Autor: Zuleide Aparecida Félix Cabral

Orientadora: Prof ${ }^{a}$ Dr $^{a}$ Anita Szochor Colli

Dissertação de Mestrado apresentada à Universidade de São Paulo, em 13/8/98.

As alterações menstruais na adolescência foram por muito tempo consideradas próprias da idade e limitadas a este período. No entanto, a possibilidade de que esta irregularidade possa ser causada por situações outras que não a assincronia temporária funcional do eixo hipotálamo, hipófise e gônadas, torna relevante o estudo do tema. Essa monografia se propôs à revisar os dados disponíveis na literatura, sobre as alterações menstruais que ocorrem na adolescência e, visando seu melhor entendimento, propor critérios para as investigações das adolescentes com sangramento uterino anormal. Embora o sangramento uterino anormal na adolescência após a menarca seja atribuido ao lento desenvolvimento dos mecanismos que resultam em ciclos ovulatórios, numa percentagem muito menor, as pacientes são ovulatórias ou têm um tipo ovulatório irregular. $\mathrm{Na}$ presença de ovulação e desvio menstrual para mais, a gravidez e suas complicações, as lesões dos órgãos genitais, o uso de anticoagulantes, a doença hepática, as tireoideopatias e os problemas hematológicos devem ser afastados. As causas mais comuns do sangramento intermenstrual são o uso irregular de anticoncepcionais hormonais orais, as interações medicamentosas e as complicações relacionadas com o dispositivo intra-uterino. Nas situações de anovulação, nas adolescentes com idade ginecológica menor do que um ano, afastadas as complicações da gravidez, as doenças orgânicas e ausentes a abesidade, a acne, o hirsutismo e a anemia, a conduta expectante com controle do padrão menstrual é adotada. A persistência de irregularidade menstrual após um ano de idade ginecológica pode indicar anovulação crônica. A sindrome dos ovários policísticos é descrita como a causa mais freqüente de hiperandrogenismo em mulheres de início puberal, e associa-se à obesidade, 
a ciclos menstruais longos e amenorréicos, hirsutismo e ovários policísticos aumentados. A neurotransmissão pode ser também afetada, nos regimes de emagrecimento por restrição calórica, nas situações de exercícios físicos excessivos ou em situações de estresse. Na presença de obesidade, acne, hirsutismo e alteração menstrual, independente da idade ginecológica, a possibilidade de anovulação crônica deve ser investigada de imediato.

Palavras-chave: Adolescência. Hiperandrogenismo. Sangramento uterino disfuncional. Anovulação.

\section{Avaliação dos Padrões Vasculares Uterino e Placentário no Primeiro Trimestre das Gestações Normal e Patológica}

Autor: Marcelo Giacobbe

Orientador: Prof. Dr. Luiz Carlos Zeferino

Dissertação de Mestrado apresentada ao Curso de Pós-Graduação em Medicina, área de Tocoginecologia da Faculdade de Ciências Médicas da Universidade Estadual de Campinas para obtenção do Título de Mestre em Medicina, na área de Tocoginecologia, em 4/2/99.

Existem dúvidas e contradições nas informações sobre o padrão vascular útero-placentário no primeiro trimestre da gestação. Com o objetivo de descrever as características vasculares útero-placentárias na gestação até 14 semanas, foi realizado um estudo clínico, descritivo, comparativo, utilizando a dopplervelocimetria com mapeamento em cores endovaginal em 45 mulheres com gestação e 44 com aborto. Estudou-se a quantidade de vasos miometriais, o fluxo interviloso (FIV), os índices de resistência (IR), pulsatilidade (IP), as velocidades sistólica (VS) e diastólica (VD) das artérias miometriais. Para a análise utilizou-se o teste Qui-Quadrado, teste de Wilcoxon e a análise de regressão linear múltipla. A quantidade de vasos miometriais foi menor na gestação que no aborto $(\mathrm{p}<0,001)$. A identificação de FIV foi mais freqüente no aborto $(\mathrm{p}<0,001)$ e a gestação mostrou tendência de uma maior presença de FIV acima de 10 semanas de idade gestacional. As médias dos IR e IP da gestação foram maiores que as do aborto $(\mathrm{p}<0,03)$. Observou-se uma diminuição dos IR e IP nas artérias uterinas e arqueadas com a progressão da idade gestacional em ambos os grupos. A VS da uterina aumentou na gestação e esteve constante no aborto ao longo do primeiro trimestre. A VD da uterina apresentou aumento progressivo em ambos os grupos. As características vasculares observadas na gestação mostraram-se diferentes das do aborto na avaliação pela dopplervelocimetria com mapeamento em cores com evidências de haver uma facilitação ao fluxo sangüíneo associado ao processo de falência gestacional.

Palavras-chave: Ultra-sonografia em obstetrícia. Aborto. Gravidez normal. Dopplervelocimetria. Endometrail de Mulheres em Ciclos Estimulados para Fertilização In Vitro

Autor: Daniella Spilborghs Castellotti

Orientador: Prof. Dr. Edmund Chada Baracat

Dissertação apresentada à Escola Paulista de Medicina - Universidade Federal de São Paulo para obtenção do título de Mestre em Ginecologia, em 25/02/99.

Objetivo: Avaliar a perfusão sanguínea uterina de mulheres submetidas a fertilização in vitro, como parâmetro prognóstico da receptividade endometrial. Pacientes e Métodos: Estudaram-se, prospectivamente, 20 mulheres com idade inferior a 38 anos, $\mathrm{FSH}<15 \mathrm{mUI} / \mathrm{ml}$ e $\mathrm{E} 2<60 \mathrm{pg} / \mathrm{ml}$ no $3^{\circ}$ dia do ciclo menstrual, com cavidade uterina normal, nãofumantes e hígidas A indicação para FIV / ET foi fator masculino (45\%), fator tubário (30\%), idiopático (15\%) e endometriose (10\%). O mesmo protocolo de indução da ovulação foi utilizado em todos os ciclos. No dia da hCG, realizou-se ultra-sonografia transvaginal com dopplervelocimetria dos ramos ascendentes das artérias uterinas, das artérias arqueadas e das arteríolas espiraladas. Avaliou-se, também, o padrão subjetivo de fluxo intramiometrial. Apenas as pacientes que apresentavam eco endometrial com espessura $>7 \mathrm{~mm}$ e padrão trilaminar foram incluídas. Transferiram-se três ou quatro embriões de excelente qualidade avaliados pelo cumulative embryo score (CES). Dividiram-se as pacientes de acordo com a presença (grupo I) ou não de gravidez (grupo II).

Resultados: O IP e o IR das artérias uterinas foi significantemente menor no grupo I em relação ao grupo II. O IP e o IR das artérias arqueadas e espiraladas foram menores no grupo I em relação ao grupo II, entretanto, esta diferença não foi significante. Não observamos diferença no padrão subjetivo de fluxo entre os 2 grupos. Não ocorreu gravidez quando o IP das artérias uterinas foi maior que 3,00. A taxa de implantação foi de $20,2 \%$ e, a de gravidez, de $50 \%$.

Conclusão: O fluxo sanguíneo uterino desempenha relevante papel no processo de implantação em ciclos induzidos de fertilização in vitro.

Palavras Chaves: Fertilização in vitro. Infertilidade. Endométrio. Dopplervelocimetria. 